\title{
Masere sarımsak (Allium sativum Limne) ve Tunceli sarımsağı (Allium tuncelianum Kollman) yağlarının yoğun stoklanmış gökkuşağı alabalıklarının (Oncorhynchus mykiss W.) baz1 kan parametrelerine ve NBT (Nitroblue Tetrazolium) seviyelerine etkileri
}

\author{
Başar ALTINTERİM ${ }^{1}$,*, Önder AKSU² \\ ${ }^{l}$ Malatya Turgut Özal Üniversitesi Su Ürünleri Fakültesi, Battalgazi Yerleşkesi, Malatya. \\ ${ }^{2}$ Munzur Üniversitesi Su Ürünleri Fakültesi, Aktuluk Yerleşkesi, Tunceli.
}

Gelis Tarihi (Received Date): 01.03.2019

Kabul Tarihi (Accepted Date): 26.08.2019

\section{Özet}

Bu çalışmada, \% 2 oranında masere sarımsak (Allium sativum L.) ve Tunceli sarımsağ (Allium tuncelianum Koll.) yağlarl, ortalama ağırlıklart: $39.0 \pm 1.64$ gr. olan gökkuşă̆ alabalıklarının yemlerine ilave edilmiştir. Çalışmanın sonunda, gökkuşağl alabalıklarının kan parametreleri ve NBT (Nitroblue Tetrazolium) seviyeleri tespit edilmiştir. Sarımsak uygulamasi yapılan gruplarda, MCH, P-LCR, PCT, PLT ve MPV parametrelerinde kontrol ve stres gruplarına göre istatistiksel olarak farklilık bulunmuştur (P<0.05). WBC, LYM, MID, RBC, HGB, HCT, MCV, MCHC, RDW-SD, $R D W-C V$ ve $P D W$, değerleri arasında bir farklılık görülmemiştir (P>0.05). Sarımsak uygulamaları sonucu NBT seviyeleri önemli derecede azalma göstermiştir $(P<0.05)$. Bu durum sarımsă̆ın hücrelerdeki oksidatif stresi azalttığını göstermektedir.

Anahtar kelimeler: Alabalık, sarımsak yă̆l, Tunceli sarımsă̆l, NBT, kan parametreleri.

\footnotetext{
* Başar ALTINTERIM, basaraltinterim@gmail.com, http://orcid.org/0000-0003-4544-2163

Önder AKSU, onderaksu@munzur.edu.tr, http://orcid.org/0000-0003-3735-6732
} 


\title{
Effects of oils of macerated garlic (Allium sativum Limne) and macerated Tunceli garlic (Allium tuncelianum Kollman) on some hematological parameters and NBT (NitroblueTetrazolium) levels of rainbow trout (Oncorhynchus mykiss W.) at high stocking density
}

\begin{abstract}
In this study, 2\% of macerated garlic (Allium sativum L.) and Tunceli garlic (Allium tuncelianum Kollman) oils were added to the feeds of rainbow trout with an average weight of $39.0 \pm 1.64 \mathrm{~g}$. At the end of the study, blood parameters and NBT (Nitroblue Tetrazolium) levels of rainbow trout were determined. A statistically significant increase in the MCH, P-LCR, PCT, PLT and MPV parameters was observed in the groups with garlic application compared to the control and stress groups $(P<0.05)$, although there was a numerical increase in all blood parameters. There was no statisticall ysignificant difference between WBC, LYM, MID, RBC, HGB, HCT, MCV, MCHC, RDW-SD, RDW-CV and PDW levels (P> 0.05). NBT levels decreased significantly as a result of garlic applications $(P<0.05)$. This shows that garlic reduces oxidative stress in cells.
\end{abstract}

Keywords: Trout, garlic oil, Tunceli garlic, NBT, blood parameters.

\section{Giriş}

Sarımsak (Allium sativum L.), eski çağlardan günümüze hem yemeklere lezzet vermek, hem de hastalıklara ilaç olarak kullanılagelmiş bir bitkidir. Sarımsak ve içerdiği maddeler, immün sistem fonksiyonlarını artırıcı, kansere karşı koruyucu [1], kardiyovasküler sistemi koruyucu [2], antimikrobiyal [3] ve antioksidan [4] özelliklere sahiptirler.

Bitkiler balıklar üzerinde farklı çalışmalarda dezenfektan veya terapötikler şeklinde çeşitli çalışmalarda kullanılmaktadır [5, 6, 7, 8, 9]. Bitkiler balıklara genellikle farklı yöntemler ile direk olarak verilir veya suyun özelliklerini değiştirerek balığa etki ettirmek üzere su ortamına bırakılır [10].

Yapılan bir çalışmada masere sarımsak yağının, su buharı distilasyonuna ve taze sarımsağa göre içerdiği maddeler açısından en zengin ürün olduğunu tespit etmiştir. Özellikle tiyosülfinatlar, vinilditiinler, sülfitler ve ajoene geçişleri en yüksek seviyede elde edilmiştir [11]. Özellikle allisin (dialiltiyosülfat) sarımsağın en dikkat çekici maddesidir. Allisin, antimikrobiyal özelliği, bağışıklık hücrelerinin fagositoz fonksiyonu kolaylaştırdığı ve bakterisit aktivitelerini arttırdığı, ek olarak, doğal öldürücü hücreleri uyardığı, lizozim ve antikor cevaplarını artırdığg bildirilmektedir [12, 13].

Ezilmemiş sarımsak taneleri nispeten kokusuzdur ve aynı zamanda S-allilsisteinsülfoksit olarak da bilinen kükürt içeren bir amino asit türevi olan alliini içerir. Alliin, sarımsak kesildiğinde veya ezildiğinde aktive olan enzim alliinaz enziminin yardımıyla allisin haline dönüştürülür. Alil-2-propenetiyosülfinat olarak da bilinen 
uçucu bir bileşik olan allisin, sarımsağa keskin kokusunu verir. Allisin, antibiyotik aktivitesi olan reaktif bir oksidandır. Aslında, allisin salgılayan doğranmış sarımsak, antibiyotiklerin keşfedilmesinden önce yaraları tedavi etmek için kullanılmaktaydı. Bununla birlikte, in vivo olarak, allisin biyolojik olarak temin edilemez ve sarımsak veya sarımsak preparasyonları yedikten sonra kanda hemen hemen tespit edilemez. Allisin yağda çözünür organosülfür bileşiklerine ayrışır [14].

Tunceli sarımsağ (Allium tuncelianum Kollman), doğal olarak yetişen tek diş sarımsak olarak da bilinen Tunceli-Ovacık yöresine ait bir sarımsak türüdür. Diğer sarımsak türlerine kıyasla daha az kokuya sahiptir. Sarımsak türlerinin hepsinin antioksidan kapasiteleri yüksektir. Özellikle ihtiva ettiği allisin antioksidan kapasitenin büyük bir bölümünü oluşturur [15].

\section{Deneysel çalışmalar}

\subsection{Deneyin hazırlanmast}

Çalışmada ortalama canlı ağırlığı $39.0 \pm 1.64$ gr. olan gökkuşağı alabalıkları (n: 160) kullanılmış ve çalışma üç tekrarlı olarak gerçekleştirilmiştir. Yoğunluk stresi gruplarında; kontrol stres grubu: 50 balık, masere sarımsak yağı stres grubu: 50 balık, masere Tunceli sarımsağı yağı stres grubu: 50 balık ve normal kontrol grubunda: 10 balık, 200 litrelik tanklara yerleştirilmiştir. Çalışmada kullanılan sarımsak ve Tunceli sarımsağı Elazığ da yöresel bir satıcıdan temin edilmiştir. Masere yağın elde edilmesi için sarımsaklar 15 gün boyunca ayçiçeği yağında (1/10 oranında) bekletilmiştir. Elde edilen masere yağlar alabalıklarının yemlerine \% 2 oranında ilave edilmiştir. Tüm çalışma boyunca balıklar sabah ve akşam olmak üzere günde iki kere ticari bir alabalık yemi ile 42 gün boyunca beslenmiştir. Yemleme günlük olarak balıkların canlı ağırlıklarının ortalama \% 2'si oranında uygulanmıştır.

\subsection{Kan analizleri}

Kan alma işlemi balıklardan besleme yapılmadan gerçekleştirilmiş ve balıklar kan alma işleminden önce anestezik madde ile (Benzocaine $30 \mathrm{mg} / \mathrm{L}$ ) bayiltılmıştır. Denemeler etik kurallara uygun olarak gerçekleştirilmiştir (İnönü Üniversitesi, Tıp Fakültesi, Deney Hayvanları Etik Kurulu, Protokol No: 2013/A-71). Bayıltılan balıkların kuyruk venalarından enjektörle kan örnekleri alınarak içerisinde EDTA bulunan tüplere aktarıldı. EDTA'lı kan örneklerinden tam kan sayımı ve NBT testi, aynı gün içerisinde yapıldı. WBC (Lökosit), LYM(Lenfosit), MID (Monosit), RBC (Eritrosit), HGB (Hemoglobin), HCT (Hematokrit), MCV (Ortalama Eritrosit Hacmi), MCH (Hücre hemoglobin ortalamas1), MCHC (Ortalama Eritrosit Hacmi), RDW-SD (Kırmız1 kan hücresi dağılım genişliği-standart sapma), RDW-CV (Kırmızı kan hücresi dağılım genişliği-varyasyon katsayısı), PLT (Trombosit), MPV (Ortalama trombosit hacmi), PDW (Trombosit dağılım genişliği), PCT (Tombosit yüzdesi), P-LCR (Trombosit-hücre genişliği oranı) parametrelerinin tespiti, PROCAN PE6800VET marka tam otomatik hematoloji analiz cihazı ile gerçekleştirilmiştir.

\section{2. İstatistiksel analiz}

Elde edilen verilerin değerlendirilmesinde SPSS (Statistical Package for the Social Sciences) Version 24.0 programı kullanılmıştır. Elde edilen hematolojik verilerin değerlendirilmesi $\mathrm{P}<0.05$ güven aralığında normal dağılım göstermeyen değerler için Kruskal wallis testi yapılmıştır. İkili gruplar arasında da mann whitney u testi uygulanmıştır. 


\section{Sonuçlar ve tartışma}

MCH, PLT, MPV, PCT, P-LCR kan parametreleri ve NBT seviyelerinde istatistikî olarak anlamlı farkl1lık bulunmuștur $(\mathrm{P}<0.05)$. WBC, LYM, MID, RBC, HGB, HCT, $\mathrm{MCV}, \mathrm{MCHC}$, RDW-SD, RDW-CV, PDW, değerleri arasındaki fark önemsiz bulunmuştur $(\mathrm{P}>0.05)$. Yemlere ilave edilen sarımsak yağlarının kan ve NBT parametreleri üzerindeki etkileri Tablo 1'de sunulmuştur.

Tablo 1. Deneme gruplarındaki balıkların kan ve NBT değerleri.

\begin{tabular}{|c|c|c|c|c|}
\hline $\begin{array}{c}\text { Kan } \\
\text { parametreleri }\end{array}$ & Kontrol normal & Kontrol stres & Sarımsak stres & $\begin{array}{c}\text { Tunceli } \\
\text { sarımsağı stres }\end{array}$ \\
\hline NBT & $0.54 \pm 0.16^{\mathrm{a}}$ & $0.72 \pm 0.03^{\mathrm{ab}}$ & $0.24 \pm 0.04^{\mathrm{b}}$ & $0.22 \pm 0.01^{\mathrm{b}}$ \\
\hline MCH (pg) & $23.76 \pm 6.24^{\mathrm{a}}$ & $39.85 \pm 8.27^{b}$ & $44.77 \pm 2.21^{\mathrm{b}}$ & $47.50 \pm 0.90^{\mathrm{b}}$ \\
\hline PLT $\left(10^{3} / \mu \mathrm{L}\right)$ & $1538.66 \pm 454.5$ & $464.5 \pm 177.48$ & $52.25 \pm 28.22$ & $19 \pm 5.56$ \\
\hline MPV (fL) & $10.9 \pm 1.6^{\mathrm{a}}$ & $8 \pm 0.56^{\mathrm{a}}$ & $11.67 \pm 1.93^{\mathrm{a}}$ & $14.36 \pm 0.4^{\mathrm{b}}$ \\
\hline PCT (\%) & $1.62 \pm 0.28 \mathrm{a}$ & $0,74 \pm 0.6^{\mathrm{b}}$ & $0.02 \pm 0.05^{\mathrm{c}}$ & $0.02 \pm 0.01^{\mathrm{c}}$ \\
\hline P-LCR (\%) & $26.26 \pm 8.42^{\mathrm{a}}$ & $11.25 \pm 3.74^{\mathrm{b}}$ & $34.52 \pm 12.58^{\mathrm{c}}$ & $53.2 \pm 2.42^{\mathrm{d}}$ \\
\hline MCHC (g/dl) & $31.03 \pm 17.07$ & $44.45 \pm 1.48$ & $46.72 \pm 1.59$ & $43.73 \pm 2.34$ \\
\hline WBC $\left(10^{3} / \mu \mathrm{L}\right)$ & $41.73 \pm 10.75$ & $39.45 \pm 7.42$ & $41.68 \pm 13.64$ & $51.2 \pm 7.53$ \\
\hline LYM (\%) & $92.53 \pm 1.84$ & $88.6 \pm 6.22$ & $93.25 \pm 1.95$ & $93.4 \pm 0.75$ \\
\hline LYM\# $\left(10^{3} / \mu \mathrm{L}\right)$ & $38.66 \pm 10.34$ & $34.7 \pm 4.10$ & $38.85 \pm 12.71$ & $47.86 \pm 7.41$ \\
\hline GRAN (\%) & $2.66 \pm 0.98$ & $5 \pm 3.67$ & $2.3 \pm 0.69$ & $2.16 \pm 0.37$ \\
\hline GRAN\#(10 $/ \mu \mathrm{L})$ & $1.06 \pm 0.4$ & $2.1 \pm 1.83$ & $0.9 \pm 0.4$ & $0.9 \pm 1.1$ \\
\hline MID\#(10 $3 / \mu \mathrm{L})$ & $2 \pm 0.45$ & $2.65 \pm 1.48$ & $1.92 \pm 0.85$ & $2.23 \pm 0.11$ \\
\hline MID (\%) & $4.8 \pm 0.9$ & $6.4 \pm 2.54$ & $4.45 \pm 1.27$ & $4.43 \pm 0.47$ \\
\hline $\operatorname{RBC}\left(10^{6} / \mu \mathrm{L}\right)$ & $2.89 \pm 0.42$ & $1.73 \pm 0.54$ & $1.74 \pm 0.66$ & $2.04 \pm 0.5$ \\
\hline HGB (g/dl) & $6.96 \pm 2.41$ & $7.15 \pm 3.6$ & $7.9 \pm 3.24$ & $9.73 \pm 2.51$ \\
\hline HCT (\%) & $24.06 \pm 5.77$ & $16.2 \pm 8.62$ & $16.9 \pm 6.85$ & $22.46 \pm 6.78$ \\
\hline $\operatorname{MCV}(\mathrm{fL})$ & $84.1 \pm 19.87$ & $90.3 \pm 21.21$ & $96.25 \pm 6.21$ & $106.06 \pm 6.96$ \\
\hline RDW-SD (fL) & $65.66 \pm 10.92$ & $50.2 \pm 7.91$ & $61.35 \pm 7.58$ & $60.1 \pm 5.69$ \\
\hline RDW-CV (\%) & $17.33 \pm 7.07$ & $11.75 \pm 0.77$ & $13.57 \pm 2.01$ & $11.76 \pm 1.85$ \\
\hline PDW (\%) & $14.76 \pm 4.46$ & $8.2 \pm 0.0$ & $9.2 \pm 1.19$ & $17.1 \pm 7.34$ \\
\hline
\end{tabular}

*: Aynı satırdaki farklı harfler istatistiki bakımından önemlidir $(\mathrm{P}<0.05)$. Ortalama + standart sapma değerleri verilmiştir. 
Masere sarımsak (Elazığ) ve Masere ovacık sarımsağı yağlarının uygulandığı balıkların trombosit seviyelerinin azalması, besi yağlarında bulunan bileşiklerin antikoagülan etkisiyle stres etkilerini azaltmada rol oynayabileceği hipotezini desteklemektedir [16, 17]. Özellikle bu etki Ovacık sarımsak yağında daha belirgin olarak ortaya çıkmıştır.

Taze sarımsağın \% 1-2-3 oranlarında alabalık yemlerine ilave edilerek gerçekleştirilen bir denemede \% 1'lik grubun $\mathrm{MCH}, \mathrm{RBC}, \mathrm{HB}$, HCT değerleri istatistikî olarak önemli bulunmuştur. Bizim çalışmamızda da benzer şekilde $\mathrm{MCH}$ değeri istatistiki olarak önemli çıkmıştır. Ancak sarımsak yağları gruplarımızda ki balıklarda RBC, HB, HCT değerlerinin istatistiki olarak önemsiz olduğu belirlenmiştir [18]. Kan endeksleri (MCV, $\mathrm{MCH}$ ve $\mathrm{MCHC}$ ), çoğu hayvanda anemi tanısı için özellikle önemlidir. Çalışmamızda, en yüksek MCH düzeyi Tunceli sarımsağında tespit edilmiştir. Ayrıca normal kontrol grubuna göre stres gruplarının $\mathrm{MCH}$ seviyelerinde belirgin bir artış olduğu tespit edilmiştir. Bu nedenle, Shalby ve ark., 2006'da belirttiği gibi MCH'deki bu artış, sarımsak yağlarının eritropoezi uyardığını göstermektedir [19]. MCHC değerleri arasında önemli bir farka rastlanılmamış olmakla birlikte, stres arttıkça rakamsal olarak değerlerin yükseldiği belirlenmiştir. $\mathrm{MCH}$ ve $\mathrm{MCHC}$ değerlerinin anemi durumuna paralel olarak artış göstermesi beklenilen bir sonuçtur.

Sarımsak ekstraktı kullanılan bir diğer çalışmada ise WBC değerleri arasındaki farklılığın, bu çalışmada olduğu gibi istatistikî açıdan önemsiz olduğu bildirilmiştir [20].

$\mathrm{MCH}, \mathrm{MCHC}$, PDW, PCT seviyelerindeki artış hematopoietik organları ve immün hücreleri uyardığını ortaya koymaktadır [21].

Hastalık etkeni (Pseudomonas fluorescens) uygulanan bir çalışmada tedavi amacıyla sarımsak uygulanan grupta hastalıkla baş edebilmek açısından NBT değerinin diğer gruplara göre anlamlı şekilde yükseldiği bildirilmiştir [22]. Benzer bir çalışmada Aeromonas hydrophila enfeksiyonuna karşı tedavi uygulamasında NBT seviyelerinde artış olduğu vurgulanmıştır [23].

Daha önce yapılmış bir diğer çalışmada ise yoğun sayıda depolanmış balıkların makrofaj ve nötrofillerinin aktivasyonunda artış olduğu beyan edilmiştir [24]. Artan makrofaj ve nötrofil aktivitesi NBT seviyesinde ki artışla paralellik göstermektedir.

Yüksek yoğunlukta stoklama çalışılan benzer çalışmalarda kontrol grubuna göre artan yoğunluk ile birlikte oksijen radikallerinin üretiminin benzer şekilde arttığı görülmüştür [25].

Özellikle monosit ve nötrofillerin immün yanıtında bir indikatörü olan fagositik aktivitenin tespitinde kullanılan, NBT aktivite testine göre, denememizde stres kontrol grubunun, normal kontrol grubuna göre arttığı görülmüştür. Ayrıca sarımsak stres gruplarında bu stresi baskılayıcı ve negatif feedback etkisi gösterdiği tespit edilmiştir. Strese bağlı olarak immün sistemde meydana gelen artış ile birlikte üretilebilecek serbest radikal miktarı vücuda zarar verebilme ihtimaline karşı sarımsak grupları özellikle Tunceli sarımsağının, dengeleyici olarak görev yaptığı görülmüştür.

Çalışmamızda kullandığımız sarımsak yağlarındaki antioksidan maddeler, gerek yoğunluktan dolayı azalan oksijen miktarından kaynaklanan stresi, gerekse de yem için 
ortaya çıkan rekabet stresine bağlı olarak makrofajlar ve nötrofiller tarafindan üretilen serbest radikallerin yüksek seviyelerini düşürerek normal seviyeye getirdiğini göstermiştir. Sarımsak yă̆ gruplarındaki NBT seviyelerindeki düşüş bunun göstergesidir. Ağbaş ve ark., 2013 çalışmalarında beyan ettikleri gibi Tunceli sarımsağının NBT değerlerindeki düşüşün normal sarımsağa göre daha düşük olması ise içerdiği antioksidan maddelerin normal sarımsağa göre daha yüksek miktarda olmasından kaynaklandığı düşünülmektedir [26].

Sonuç olarak ülkemizde üretimi gerçekleştirilen ve maliyetli olmayan sarımsakların masere yağlarının, balık stresinin giderilmesinde ve profilaktif olarak kullanımı tavsiye edilmektedir.

\section{Kaynaklar}

[1] You, W.C., Blot, W.J., Chang, Y.S., Ershow, A., Yang, Z.T., An, Q., Henderson, B.E., Fraumeni, J.F. Jr, Wang, T.G., Allium vegetables and reduced risk of stoma chcancer, Journal of the National Cancer Institute, 81, 2, 162-4, (1989)

[2] Amagase, H., Petesch, B.L., Matsuura, H., Kasuga, S., Itakura, Y., Intake of garlic and its components, The Journal of Nutrition, 131, 3, 955-962, (2001).

[3] Erkan, N. and Bilen, G., Effect of essential oil streatment on the frozen storagestability of chub mackerel fillets, Journal für Verbraucher schutz und Lebensmittelsicherheit, 5: 101-110, (2010).

[4] Imai, J., Ide, N., Nagae, S., Moriguchi, T., Matsuura, H., Itakura, Y., Antioxidant and radical scavenging effects of aged garlic extract and its constituents, Planta Medica, 60, 5, 417-20 (1994).

[5] Chang, S.T., Chen, P.F. and Chang, S.C., Antibacteriel activity of leaf essantial oils and their consituents from Cinnamon osmophloeum, Journal of Ethanophermacology, 77, 123-127 (2001).

[6] Chorianopoulos, N.G., Giaouris, E.D., Skandamis, P.N., Haroutounian, S.A. and Nychas, G.J.E., Disinfectant test against monoculture and mixed-culture biofilms composed of technological, spoilage and pathogenic bacteria: Bactericidal effect of essential oil and hydrosol of Satureja thymbra and comparison with standard acidbase sanitizers, Journal of Applied Microbiology, 104, 1586-1596 (2008).

[7] Gulec, A.K., Altinterim, B. and Aksu, O., Determination of lethal concentration (LC50) values of Cinnamomum zeylanicum hydrosol on carp fish, Iranian Journal of Fisheries Sciences, 12, 1, 34-44, (2013).

[8] Altınterim, B., Kutluyer, F. and Aksu, O.. Oksijen Radikal Absorbans Kapasitesi (ORAK) Seviyeleri Farklı Bitki Masere Yağlarının Yoğun Stoklanmış Gökkuşağı Alabalıklarının (Oncorhynchus mykiss) Bazı Kan Parametrelerine Etkileri, Atatürk Üniversitesi Veteriner Bilimleri Dergisi, 13, 1, 63-69, (2018a).

[9] Altınterim, B., Öztürk, E., Kutluyer, F. and Aksu, O., Yeşil Çay Yağının Gökkuşağı Alabalıklarının (Oncorhynchus mykiss) Yem Değerlendirme Oranına ve Hematolojik Parametrelerine Etkileri, Atatürk Üniversitesi Veteriner Bilimleri Dergisi, 13, 2, 159-164, (2018b). 
[10] Altınterim, B., Gulec, A.K. and Aksu O., Determination of Safety Dose of Eucalyptus camaldulensis Hydrosol on Mirror Carp (Cyprinus carpio), Fresenius Environmental Bulletin, 21, 5a, 1219-1222, (2012).

[11] Brace, L.D., Cardiovascular Benefits of Garlic (Allium sativum L), The Journal of Cardiovascular Nursing, 16, 4, 33-49, (2002).

[12] Lee, J.Y. and Gao, Y., Review of the application of garlic, Alliums sativum, in aquaculture, Journal of the World Aquaculture Society, 43, 4, 447-458, (2012).

[13] Talpur, A.D. and Ikhwanuddin, M., Dietary effects of garlic (Allium sativum) on haemato-immunological parameters, survival, growth, and disease resistance against Vibrio harveyi infection in Asian seabass, Latescal carifer (Bloch), Aquaculture, 364-365: 6-12, (2012).

[14] Freeman, F., and Kodera, Y., Garlic chemistry: stability of S-(2-Propenyl) 2Propene-1-sulfinothiolate (Allicin) in blood, solvents and simulated physiological fluids, Journal of Agricultural and Food Chemistry, 43, 9, 2332-2338, (1995).

[15] Yumrutaş, Ö., Demirörs, Saygıdeğer, S., Doğan, M. The in vitro antioxidant activity of Allium tuncelianum: An endemic. Journal of Appliedbiological Sciences, 3, 3, 61-64, (2009).

[16] Chan, K., Yin, M. and Chao, W., Effect of diallyl trisulfide-rich garlic oil on blood coagulation and plasma activity of anticoagulation factors in rats, Food and Chemical Toxicology, 45, 3, 502-507, 2007.

[17] Ohaeri, O.C. and Adoga G.I. Anticoagulant Modulation of Blood Cells and Platelet Reactivity by Garlic Oil in Experimental Diabetes Mellitus, Bioscience Reports, 26, 1, DOI: 10.1007/s10540-006-9004-1, (2006).

[18] Farahi, A., Kasiri, M., Sudagar, M., Iraei, M.S. and Shahkolaei M.D., Effect of garlic (Allium sativum) on growth factors, some hematological parameters and body compositions in rainbow trout (Oncorhynchus mykiss), AACL Bioflux, 3, 4, 317-323, (2010).

[19] Shalaby, A.M.I., Khattab, Y.A., Abdel Rahman, A.M., Effects of Garlic (Allium sativum) and chloramphenicol on growth performance, physiological parameters and survival of Nile tilapia (Oreochromis niloticus), The Journal of Venomous Animals and Toxins including Tropical Diseases, 12, 2, 172-201, (2006).

[20] Breyer, K.E., Getchell, R.G., Cornwell, E.R. and Wooster, G.A., Efficacy of an Extract from Garlic, Allium sativum, Against Infection with the Furunculosis Bacterium, Aeromonas salmonicida, in Rainbow Trout, Oncorhynchus mykiss. Journal of The World Aquaculture Society, 46, 3, 273-282, (2015).

[21] Hamadouche, NA., Lazeb, H., Kaddouri, A., Guellil, H., Slimani, M. and Aoues A., Ameliorated effects of green tea extract on lead induced kidney toxicity in rats, Algerian J Nat Prod, 3, 130-137, (2016).

[22] Diab, A.S., Aly, S.M., John, G., Abde-Hadi, Y. and Mohammed, M.F., Effect of garlic, black seed and Biogen as immunostimulants on the growth and survival of Nile tilapia, Oreochromis niloticus (Teleostei: Cichlidae), and their response to artificial infection with Pseudomonas fluorescens, African Journal of Aquatic Science, 33, 1, 63-68, (2008).

[23] Nya, E.J. and Austin, B. Use of garlic, Allium sativum, to control Aeromonas hydrophila infection in rainbow trout, Oncorhynchus mykiss (Walbaum), Journal of Fish Diseases, 32, 11, 963-70, (2009). 
[24] Siwicki, A.K. and Studnicka, M. The phagocyticability of neutrophils and serum lysozme activity in experimentally infected carp, Cyprinus carpio L., Journal of Fish Biology, 31, A, 57-60, (1987).

[25] Ruane, N.M., Carball, E.C. and Komen, J., Increased stocking density influence the acute physiological stres response of common carp Cyprinus carpio (L.), Aquaculture Research, 33, 777-784, (2002).

[26] Ağbaş, B., Karakuş, D., Adıgüzel, R., Keser, S. and Demir, E. Tunceli Sarımsağının (Allium tuncelianum) Toplam antioksidan Özelliklerinin ve Kuru Madde İçeriğinin Normal Sarımsak (Allium sativum) ile karşılaştırılması. Munzur Üniversitesi, Bilim ve Gençlik Dergisi, 1, 2, 50-62, (2013). 